\title{
Research on the viewpoint of sustainable social system construction
}

\author{
Yuutarou Hayashi, ${ }^{1,2}$ \\ ${ }^{1}$ The Academic Society of Japan councilor \\ ${ }^{2}$ Osaka Christian college, Osaka, Japan \\ general@siren.ocn.ne.jp
}

Keywords: Symbiosis, high-dimensional society, new value creation, academic fusion Perspective, Society after petroleum civilization, sustainable society business administration, symbiosis business administration, truth realization society-oriented.

\begin{abstract}
A sustainable society is a society that is necessary for the survival of mankind for the future such as military, peace, symbiosis, governance, population, education, resources, food, energy, crustal deformation, weather, environment, medical care, the society considered comprehensively. Sustainable social system research is to investigate how to respond to various problems progressing on a global scale and enable human beings to survive. Because of its diversity, research on individual theories and comprehensive research and advancement of comprehensive survival studies by Crosssectoral interdisciplinary research are necessary. From the perspective of sustainable social system management studies, co-existence management studies, multicultural management, multi-religious business administration, control business management, and management theory of the sustainable society advocated by the writer for a long time ago I will discuss it in detail.
\end{abstract}

\section{Introduction}

Peace and symbiotic thinking are important issues for building a sustainable social system. The way to build symbiosis is the collaboration of organizations with people over the ethnic groups and various differences, and expansion of culture propagation and exchange is necessary. In order to create a society that can coexist beyond ethnicity and various kinds of differences, we must establish a symbiotic society by establishing mutual respect for culture and dignity and self-establishment not being deceived by organizational psychology. Regardless of ethnic, cultural and historical background, exchange between the country / university / company / people etc. is indispensable for achieving symbiosis. The fundamentals of building a sustainable society lie in the establishment of peace and rehabilitation of symbiotic awareness. To that end, it is necessary to enhance education on sustainable social systems and to improve social perceptions of sustainability globally and to train peace building.

\section{Main subject}

A sustainable society, we must aim for high-dimensional society after petroleum civilization / new value creation after petroleum civilization, Cross-sectoral interdisciplinary fusion. etc. (Figure 1)

\begin{tabular}{|c|c|c|}
\hline $\begin{array}{l}\text { Contemporary } \\
\text { society }\end{array}$ & $\begin{array}{l}\text { Examination of } \\
\text { social direction } \\
\text { in the future }\end{array}$ & $\begin{array}{l}\text { - Promotion of Cross- sectoral } \\
\text { interdisciplinary } \\
\text { - Promotion of new value creation }\end{array}$ \\
\hline $\begin{array}{l}\text { - Symbiosis society } \\
\text { - High dimensional } \\
\text { society }\end{array}$ & $\begin{array}{l}\text { Society after } \\
\text { petroleum } \\
\text { civilization }\end{array}$ & $\begin{array}{l}\text { - Enhancement of life dignity and } \\
\text { symbiosis education }\end{array}$ \\
\hline
\end{tabular}

Figure 1. Sustainable social system construction phase diagram 
1. High-dimensional society-oriented. A high-dimensional society is a high-level social situation that is difficult to achieve at the present time, but it is a desire of humanity and it is necessary to make efforts to realize. A high-dimensional society is a schematic model of the following societies [1].

1. Harmonious coexistence (multiethnic ethnicity, multi-religion - multicultural symbiosis and conflict) and symbiosis with nature $\cdot$ symbiosis with the earth and space symbiosis

2. Establishment of permanent peace (it is necessary to ban battle between biological same life forms)

3. Formation of the World Federation (The United Nations is a coalition of sovereign states and there is a limit in action)

4. Correcting various disparities and overcoming poverty

5. Promotion of international interchange such as resources, energy and food

6. Improvement of the global environment is required.

7. Establishment of governance philosophy and realization of philosophical reign (fundamentals of truth, justice, equality, symbiosis)

8. Fused society of culture and religion by multi-values (Omitted below)

2. Society after petroleum civilization. The energy used by human beings is expected to further increase in the future due to world population increase and social progress. Petroleum, natural gas, coal, etc. are limited resources and it is obvious that it will be depleted in the future, so the next base energy must be established. Post-petroleum civilization is a model roughly modeling the following society [1].

1. Based on next generation nuclear power generation / new energy / renewable energy

2. Suppress production of petroleum synthetic chemical products (new product development)

3. Promoting recycling and energy conservation

4. Electric civilization - Advanced information and communication civilization - Society in which advanced technology society continues to develop

5. A sustainable society utilizing integrated survival studies

6. A society promoting the Green Economy Initiative

3. Future social direction. The outline of the social trend of the future from the global perspective will be as follows $[2,4,5]$ :

1. Harmonious symbiosis / Nature symbiosis, Earth symbiosis, Peace symbiosis and Globalism develop, New value creation develops.

2. Going from petroleum energy to next generation energy.

3. Advanced society and advanced information communication society develop.

4. Improve disaster prevention and disaster and improve infrastructure repair technology and durability

5. The global environment is improving (measures to prevent desert spreading and measures to curb global warming are also necessary)

6. Population growth and employment opportunities expand (employment is dignity of personality $\cdot$ strengthening of education and training is also necessary)

7. It is necessary to expand population growth and measures for an aging society.

8. The correction of various gaps and the correction of discrimination progresses.

9. It becomes a high-risk society, prevention of war / conflict and prevention of terrorism are necessary.

10. The development of an inclusive society (physical / mentally disabled, unemployed, victims, refugees etc. personality and dignity perspective should be embodied) 
4. Creation of new value. Today is the era of new value creation, people adapt to the political situation/economic situation/the public sentiment etc, self-change/consciousness change/value created people, regions, ethnicities/country survive. Creation of sustainable social systems requires creation of new value. The reason is that the development of science and technology/information and communication technology and various disciplines is fast and it has become insufficient in correspondence with past values. For that reason, it is important to review the current value standards. It is necessary not to deny the value theory so far, but to evolve this value theory. The creation of new value is to incorporate the results of the current academic study to a large extent. For example, it is a global issue such as environmental conservation, post-petroleum civilization, new energy development, simulation of social model by analysis of big data, construction of food production increase model corresponding to the rapid population increase, construction of next generation business model. For that purpose, it is necessary to promote contemporary consideration of value theory and "Cross-sectoral interdisciplinary research viewpoint" [3].

5. Cross-sectoral Interdisciplinary research viewpoint. Cross-sectoral Interdisciplinary research is integration of knowledge, and in collaboration research with different fields of values, there are many labor, such as conflict, difficulty understanding, difference in value standards, but in search of common points and places accessible to each other, "Aufheben" Think of. In other words, we will reconsider and evolve the basic definitions of each field and consider changing the thought pattern. Open new academic societies based on new value if necessary to explore new fields without being bound by current common knowledge of academics. To that end, it is necessary to promote Innovation by thinking from an international perspective (intercultural / different dimension thinking) and high dimensional thought and expansion thinking [2].

\section{Element to promote the cross-sectoral interdisciplinary fusion}

Elements that promote interdisciplinary inter-disciplinary integration:

1. A perspectives on building a sustainable social system and a global perspective are necessary

2. Relaxation of the field of specialization is necessary

3. Development of new social needs, future prospects and establishment of application strategies of academic study are necessary

4. Since the phenomenon analysis becomes complicated, it is necessary to construct a higher-order complex system

5. Long-term axial consideration is necessary

6. Cooperation between natural science and humanities / social science is necessary

7. It is necessary to construct a system of interdisciplinary research at universities and research institutes

8. It is necessary to construct a new system for evaluating researchers

9. Training of innovation talent who challenges new areas is necessary

\section{Summary}

To build a sustainable social system, it is essential to end war / conflict and maintain peace, but the outline of other major elements is as follows:

1. It is necessary to create new value creation, cross-sectoral interdisciplinary research, correction of distortion of Globalism, modification of market principle, modification of demerit, socialism and nationalism faults.

2. Relevant laws and regulations - It is necessary to develop international treaties

3. It is necessary to expand education on sustainable social system construction and peace building.

4. It is necessary to creatively study symbiosis / cooperation / new culture. 
5. It is necessary to reduce all poverty and hunger, unemployed and discrimination.

6. It is necessary to always adopt the pursuit of truth and justice as a social infrastructure.

7. It is necessary to strengthen response to incorrect thinking (e.g. specific ethnic aversion, nihilism, etc.).

8. Extreme populism must be eliminated.

9. Because the Earth's crust is in active phase, it is necessary to deal with disaster prevention and abnormal weather.

10. It is necessary to advance the elucidation of discontinuous parts and unclear parts of human history such as ancient history and extinct civilization and to utilize it for future social construction.

11. together enhance the professional development of human resources education, there needs to be co-workers allowed to understand the significance of the people.

12. It is necessary to prevent misuse or interference from nationalism, nationalism, religion, etc.

13. Promotion of employment of women and promotion of employment of elderly who wish to work and limitation of child labor are necessary. It is necessary to improve gender equality and empowerment of women.

14. In the future society it is necessary not to use war as a means of solving conflict and strengthen awareness of life dignity and symbiosis.

15. Strengthening correspondence to artificial intelligence inhumanity is necessary.

16. Correspondence to big data includes collection, selection, storage, retrieval, sharing, transfer, analysis, visualization. Various tools for handling big data have been developed to handle various aspects of data, and their use is necessary. (Below omitted)

\section{References}

[1] Yuutarou HAYASHI, "Creation (Part 1) of new business practices by sustainable social system construction" Japan business practices Society Journal of the Kinki block study Group 48th Conference of the Japan Society of Applied Business Studies Group(2011) 03

[2] Yuutarou HAYASHI, "the creation of new business practices by sustainable society system construction" (Part 3) Abstract of the 32th Conference of the Japan society of applied business studies (2013) 30-33

[3] Yuutarou HAYASHI, "the creation of new business practices by sustainable society system construction" (Part 5) Abstract of the 33th Conference of the Japan society of applied business studies (2014) 86-89

[4] Yuutarou HAYASHI, "the creation of new business practices by sustainable society system construction" (Part 7) Abstract of the 34th Conference of the Japan society of applied business studies (2015) 98-102

[5] Yuutarou HAYASHI, "business practices Studies Principles of construction method (Part 1) Business practices science of "business practices Studies Principles of construction method (Part 1) - Business practices science of uniqueness " Abstract of the 35th Conference of the Japan society of applied business studies (2016) 80-83 